\title{
CARACTERIZAÇÃO BIOQUÍMICA E PERFIL DE SENSIBILIDADE AOS ANTIMICROBIANOS DE AGENTES BACTERIANOS ISOLADOS DE MASTITE SUBCLÍNICA OVINA NA REGIÃO OESTE DE SANTA CATARINA
}

\author{
Guilherme Drescher, ${ }^{1}$ Samara Paula Mattiello, ${ }^{2}$ Rodolfo de Moraes Peixoto, ${ }^{3}$ \\ Agueda Castagna de Vargas, ${ }^{4}$ Marlon Nadal Maciel ${ }^{5}$ e Mateus Matiuzzi da Costa ${ }^{6}$ \\ 1. Médico veterinário autônomo \\ 2. Estudante de Graduação da Faculdade de Veterinária, UNOESC \\ 3. Mestrando do Programa de Pós-Graduação em Ciência Animal, UNIVASF \\ 4. Professora adjunta, Departamento de Medicina Veterinária Preventiva, UFSM \\ 5. Professor adjunto, Centro de Ensino Superior Norte do Rio Grande do Sul, UFSM \\ 6. Professor adjunto, Colegiado de Zootecnia, UNIVASF. E-mail: mateus.costa@univasf.edu.br
}

RESUMO

A mastite é uma enfermidade que acomete principalmente animais com aptidão leiteira, ocasionando uma série de prejuízos aos produtores de ovinos de leite e corte. Objetivou-se avaliar o perfil de sensibilidade aos antimicrobianos dos principais agentes causadores de mastite em ovelhas. Foram analisadas 163 amostras de leite, sendo utilizado o teste Whiteside Modificado (WSM), além do cultivo das amostras em ágar sangue ovino 5\% (AS). Das 163 amostras analisadas, observou-se que $23,31 \%$ e $14,72 \%$ foram positivas e fortemente positivas, respectivamente, no teste WSM. Os principais agentes isolados foram Staphylococcus spp. (31,39\%), Acinetobacter spp. (10,50\%), Enterobacter aerogenes (10,50\%),
Escherichia coli (8,20\%) e Aeromonas spp. (6,70\%). O perfil de sensibilidade aos antimicrobianos apresentou grande variação, com a novobiocina demonstrando o menor percentual de sensibilidade $(10,46 \%)$. A maior taxa de susceptibilidade foi observada para a associação de lincomicina com estreptomicina $(86,02 \%)$. Neste estudo, observou-se que os Staphylococcus spp. são os agentes comumente envolvidos nos casos de mastite subclínica em ovelhas. A associação entre lincomicina e estreptomicina e josamicina e trimetoprim constituiu as drogas mais eficientes nos testes de sensibilidade in vitro contra os agentes da mastite ovina.

PALAVRAS-CHAVES: Mastite, microrganismos, resistência antimicrobiana, teste Whiteside.

\section{BIOCHEMICAL CHARACTERIZATION AND PROFILE OF ANTIBIOTICS SENSIBILITY TO BACTERIA AGENTS RESPON- SIBLE FOR OVINE SUBCLINICAL MASTITIS IN WEST REGION OF THE SANTA CATARINA}

Ovine mastitis is an infectious disease associated to economic losses in dairy and meat sheep. The present study aims to determine the antimicrobial drug patterns of the most frequent etiologic agents of ovine mastitis. We analyzed 163 milk samples using Whiteside test, besides the bacteriological culture in ovine blood agar 5\% (AS). From 163 analyzed samples $23.31 \%$ and 14.72\% were positive and strongly positive, according to the Whiteside test. The most frequent etiologic agents of ovine mastitis isolated in the present study were: Staphylococcus spp. (31.39\%), Acinetobacter spp. (10.50\%), Enterobacter aerogenes (10.50\%), Escherichia coli (8.20\%) and Aeromonas spp. (6.70\%). The sensitivity patterns to antimicrobial drugs showed high variation. The small sensitivity was observed to novobiocin $(10.46 \%)$. The higher sensitivity was detected to lyncomicin + streptomicin association $(86.02 \%)$. In our study we conclude that Staphylococcus spp. are the most frequent bacterial agents envolved in subclinical mastitis in sheep. The association of lyncomicin + streptomicin and josamicin + thrimetoprin were more efficient in vitro sensitivity tests.

KEY WORDS: Mastitis, microorganisms, antimicrobial resistance, Whiteside test. 


\section{INTRODUÇÃO}

A mastite é a inflamação da glândula mamária, que ocasiona alterações físicas, químicas e bacteriológicas no leite, além de produzir alterações no tecido da glândula mamária (BLOOD et al., 1994). A incidência anual da mastite clínica em pequenos ruminantes está geralmente abaixo de $5 \%$, podendo aumentar esporadicamente. Por outro lado, a prevalência de mastite subclínica tem sido estimada entre $5 \%$ a $30 \%$ (BERGONIER \& BERTHELOT, 2003; CONTRERAS et al., 2003). As perdas na produção de leite e aumento na contagem de células somáticas (CCS) em cabras e ovelhas infectadas têm sido amplamente documentados (LEITNER et al., 2004), e parece que ovelhas possuem maior vulnerabilidade que cabras para perdas no rendimento de leite (SILANIKOVE et al., 2005).

Vários patógenos podem causar mastite, mas Staphylococcus spp. são diagnosticados com maior frequência como causa de infecções intramamárias em cabras e ovelhas. Outros patógenos como o Streptococcus spp., microrganismos da família Enterobacteriaceae, Pseudomonas aeruginosa, Mannheimia haemolytica, corinebactérias e fungos podem produzir infecções intramamárias em pequenos ruminantes, mas em menor proporção (BERRIATUA et al., 2001; BERGONIER \& BERTHELOT, 2003; CONTRERAS et al., 2003; GONZALO et al., 2004).

Infecções intramamárias causadas por $S$. aureus têm merecido atenção especial, pois essa bactéria é responsável por dois tipos graves de mastite: a mastite gangrenosa e a subclínica. $S$. aureus produz algumas toxinas importantes que contribuem para a patogênese da mastite e também estão associadas a doenças alimentares, mesmo com leite pasteurizado, devido à contaminação por enterotoxinas termoestáveis (CONTRERAS et al., 2007). Staphylococcus coagulase negativa $(\mathrm{CNS})$ possuem maior prevalência na etiologia da mastite subclínica em ruminantes leiteiros. Embora menos patogênico que Staphylococcus aureus, CNS podem também produzir mastite subclínica persistente, significativo aumento de CCS e mastite clínica, além de produzir enterotoxinas termoestáveis (DEINHOFER \& PERNTHANER, 1995; UDO et al., 1999).

O diagnóstico das mastites em ovelhas pode ser realizado na propriedade através de testes como o CMT (California Mastitis Test) e também o Whiteside.
Ambos os testes possuem o mesmo mecanismo de ação e são usados para acompanhar casos de mastite subclínica no rebanho, e tem como fundamento a detecção do aumento do número de leucócitos e células de descamação. O Teste Whiteside (TWS) e o California Mastitis Test (CMT) detectam indiretamente a presença ou o aumento do número de leucócitos no leite (HUESTON et al., 1986). Outro teste usado na detecção de mastite em animais é a contagem de células somáticas (CCS) no leite. Este método é realizado em laboratório e apresenta resultados fidedignos (CLEMENTS et al., 2003).

Várias drogas antimicrobianas têm sido empregadas no tratamento da mastite ovina, no entanto, poucos são os trabalhos sobre o perfil de sensibilidade aos antimicrobianos dos isolados bacterianos causadores da enfermidade. De acordo com CONTRERAS et al. (2007), a terapia intramamária da mastite ovina é realizada com drogas de indicação para a espécie bovina, dada a escassez de produtos para pequenos ruminantes. Assim, a diversidade dos agentes da mastite ovina e a sua crescente resistência aos antimicrobianos convencionais alertam para a necessidade da realização de testes de sensibilidade in vitro, visando à terapia correta para os casos de mastite na propriedade.

O presente estudo teve por objetivo avaliar o perfil de sensibilidade aos antimicrobianos dos principais agentes causadores de mastite em ovelhas clinicamente saudáveis.

\section{MATERIAL E MÉTODOS}

A coleta das amostras de leite foi realizada durante o período de setembro a novembro de 2006 . $\mathrm{O}$ estudo foi realizado em nove propriedades rurais da região oeste do estado de Santa Catarina, entre os quais Xanxerê, Chapecó, Bom Jesus, Xaxim, Lageado Grande, Marema e Cordilheira Alta. Os animais utilizados no trabalho possuíam aptidão mista (carne e leite), sendo explorados em sistema extensivo. Utilizaram-se 84 fêmeas ovinas mestiças, entre a segunda e a quinta lactação.

Coletaram-se as amostras de leite após lavagem da glândula mamária e secagem com papel toalha, sendo desprezados os três primeiros jatos. Foram utilizados frascos estéreis, identificados e acondicionados sob refrigeração $\left(4^{\circ} \mathrm{C}\right)$ em caixas isotérmicas até sua 
chegada no Laboratório de Microbiologia da UNOESC. De cada animal, coletaram-se duas amostras, uma de cada teto, totalizando 163 amostras de leite avaliadas.

No laboratório, com o auxílio de uma pipeta estéril, foi realizado o teste Whiteside Modificado $(\mathrm{NaOH}$ $4 \%$ ), na proporção de quatro partes de leite para uma parte de reagente. Usou-se o Whiteside para quantificar a resposta inflamatória presente nas amostras, sendo interpretado da seguinte forma: negativa (ausência de grumos), $(+)$ fracamente positiva (poucos grumos), $(++)$ positiva (moderado número de grumos) e $(+++)$ fortemente positiva (elevado número de grumos).

Para o isolamento bacteriano, as amostras foram semeadas em ágar sangue ovino a 5\%, com o auxílio de uma alça de platina e após levadas para a estufa a $37^{\circ} \mathrm{C}$. Efetuou-se a leitura das placas em 24 e 48 horas, e identificaram-se os agentes bacterianos por meio de características morfológicas, bioquímicas e tintoriais (QUINN et al., 1994).

Determinou-se o perfil de sensibilidade dos microrganismos por meio do método de difusão em disco Kirby-Bauer modificado (NCCLS, 1999). Os isolados foram semeados em Müller Hinton caldo e incubados a $37^{\circ} \mathrm{C}$ até obtenção de turvação conforme a escala 0,5 de Mac Farland. Com auxílio de um swab, semearam-se os isolados em placas de Petri contendo Müller Hinton ágar. Logo após, foram aplicados os discos impregnados com as drogas antimicrobianas que incluíram: novobiocina $(30 \mu \mathrm{g})$, lincomicina $(2 \mu \mathrm{g})$, eritromicina $(15 \mu \mathrm{g})$, amoxicilina $(10 \mu \mathrm{g})$, josamicina $(30 \mu \mathrm{g})$, ceftiofur $(30 \mu \mathrm{g})$, josamicina associada à trimetoprim, doxiciclina $(30 \mu \mathrm{g})$, cefalexina $(30 \mu \mathrm{g}) \mathrm{e}$ lincomicina associada à estreptomicina. Incubaram-se as placas em estufa durante 24 horas a $37^{\circ} \mathrm{C}$. Após a leitura dos halos, foi determinado o perfil de sensibilidade dos isolados.

\section{RESULTADOS E DISCUSSÃO}

Das 163 amostras analisadas, observou-se que $23,31 \%(38 / 163)$ e $14,72 \%(24 / 163)$ foram positivas e fortemente positivas, respectivamente, no teste Whiteside, indicando um aumento do número de células somáticas. Tais dados revelam uma frequência de mastite subclínica de 38\% nos rebanhos estudados. As amostras sem crescimento bacteriano em cultivo corresponderam a 53,37\% (87/163), das quais $42,53 \%$ (37/87) apresentaram resultado negativo no teste Whiteside e $39,08 \%(34 / 87)$ foram fracamente positivas para este teste. Os resultados positivos no Whiteside, mas negativos no exame microbiológico, podem indicar um processo inflamatório de origem não bacteriana, pois, segundo GONZÁLEZ-RODRÍGUEZ \& CÁRMENES (1996), o Whiteside é um teste importante no diagnóstico de mastite subclínica em ruminantes.

Com relação aos resultados da lactocultura, $53,37 \%(87 / 163)$ das amostras apresentaram resultado negativo e 46,63\% (56/163) mostraram crescimento bacteriano. Os microrganismos isolados das 163 amostras de leite de ovelha encontram-se na Tabela 1, sendo observada maior frequência de Staphylococcus spp. (31,39\%). O isolamento de microrganismos do gênero Staphylococcus spp. reforça a sua importância na etiologia de mastite subclínica (CONTRERAS et al., 2007). MARGUET et al. (2000) avaliaram vários casos de mastite subclínica em ovelhas, sendo isolados apenas microrganismos do gênero Staphylococcus spp. COUTINHO et al. (2006) realizaram um estudo etiológico da mastite ovina no Estado da Bahia, sendo observada elevada frequência de Staphylococcus coagulase negativa $(57,6 \%)$, seguido do $S$. aureus (15,2\%), Micrococcus spp., (15,2\%) e Streptococcus spp. $(12 \%)$.

TABELA 1. Isolamento de microrganismos em 163 amostras de leite de fêmeas ovinas, no oeste de Santa Catarina

\begin{tabular}{lcc}
\hline \multirow{2}{*}{ Microrganismos } & \multicolumn{2}{c}{ Isolamento } \\
\cline { 2 - 3 } & N. ${ }^{\text {a }}$ absoluto & $\begin{array}{c}\text { Frequência } \\
(\%)\end{array}$ \\
\hline Staphylococcus spp. & 24 & 34,28 \\
Staphylococcus aureus & 02 & 2,85 \\
Staphylococcus epidermidis & 01 & 1,42 \\
Acinetobacter spp. & 09 & 12,85 \\
Enterobacter aerogenes & 09 & 12,85 \\
Escherichia coli & 07 & 10,00 \\
Aeromonas spp. & 06 & 8,57 \\
Streptococcus spp. & 04 & 5,71 \\
Pseudomonas spp. & 04 & 5,71 \\
Corynebacterium spp. & 02 & 2,85 \\
Klebsiella spp. & 01 & 1,42 \\
Alcaligenes faecalis & 01 & 1,42 \\
\hline
\end{tabular}


Neste trabalho foram isolados agentes pertencentes à família Enterobacteriaceae, tais como Escherichia coli, Enterobacter aerogenes e Klebsiella spp. O isolamento de microrganismos da família Enterobacteriaceae associado à ausência de sinais clínicos nos animais não é um achado comum, já que as mastites causadas por enterobactérias geralmente demonstram evidências clínicas. As enterobactérias são consideradas importantes agentes das mastites ambientais (PRESTES et al., 2003). Dentre os principais agentes ambientais, a Escherichia coli destaca-se, em virtude do severo quadro clínico apresentado (BRABES et al., 2003).

O perfil de sensibilidade dos microrganismos isolados aos antimicrobianos apresentou grande variação, com a novobiocina demonstrando o menor percentual de sensibilidade $(10,46 \%)$, seguida da eritromicina (16,29\%), lincomicina $(17,43 \%)$, e da amoxicilina (19,77\%). SANTOS (2006), avaliando o perfil de sensibilidade de Staphylococcus spp. e enterobactérias isoladas de mastite recorrente em oito rebanhos da região de Uberlândia-MG, observou que $73,68 \%$ dos isolados de Staphylococcus spp. foram resistentes à eritromicina e 76,92\% das enterobactérias isoladas foram resistentes à amoxicilina.

LOLLAI et al. (2008) analisaram o perfil e a evolução da resistência antimicrobiana de patógenos da mastite ovina entre o período de 1995 e 2004, identificando que a resistência de Staphylococcus spp. à penicilina pareceu ser menor do que o relatado em outros estudos $(4,1 \%$ de cepas resistentes de $S$. aureus; $15,3 \%$ de Staphylococcus coagulase negati- va). Índices maiores de resistência foram observados para aminoglicosídeos. Os autores concluíram que o perfil encontrado parece confirmar a resistência menor dos patógenos de ovinos, quando comparados aos de origem bovina.

A elevada resistência dos isolados à novobiocina, fato observado neste trabalho, difere do descrito por FREITAS et al. (2005), que encontraram maiores taxas de sensibilidade isolados de mastite para a novobiocina (71\%). Contudo, foi observada concordância para os valores elevados de resistência tanto para a amoxicilina quanto para a penicilina. A amoxicilina pertence ao mesmo grupo de antibióticos betalactâmicos e geralmente os isolados de Staphylococcus spp. são bastante resistentes (acima de 70\%) à penicilina $\mathrm{G}$, bem como ampicilina e carbenicilina (TAVARES, 2000). Porém, LANGONI et al. (2000), avaliando a eficácia do tratamento da mastite por meio da administração da amoxicilina, enrofloxacina e a associação de ambos, encontraram $84,6 \%$ e $75 \%$ de sensibilidade para agentes isolados de casos de mastite subclínica e clínica, respectivamente.

As maiores taxas de susceptibilidade foram observadas para a associação de lincomicina com estreptomicina $(86,02 \%)$, josamicina com trimetoprim $(67,44 \%)$ e doxiciclina $(61,44 \%)$ (Figura 1$)$. As associações entre antimicrobianos aumentam as taxas de susceptibilidade dos isolados bacterianos, devido ao aumento do espectro de ação, fato este importante, já que a mastite é uma enfermidade de etiologia múltipla, sendo isolados microrganismos gram positivos e gram negativos (LANGONI et al., 2000).

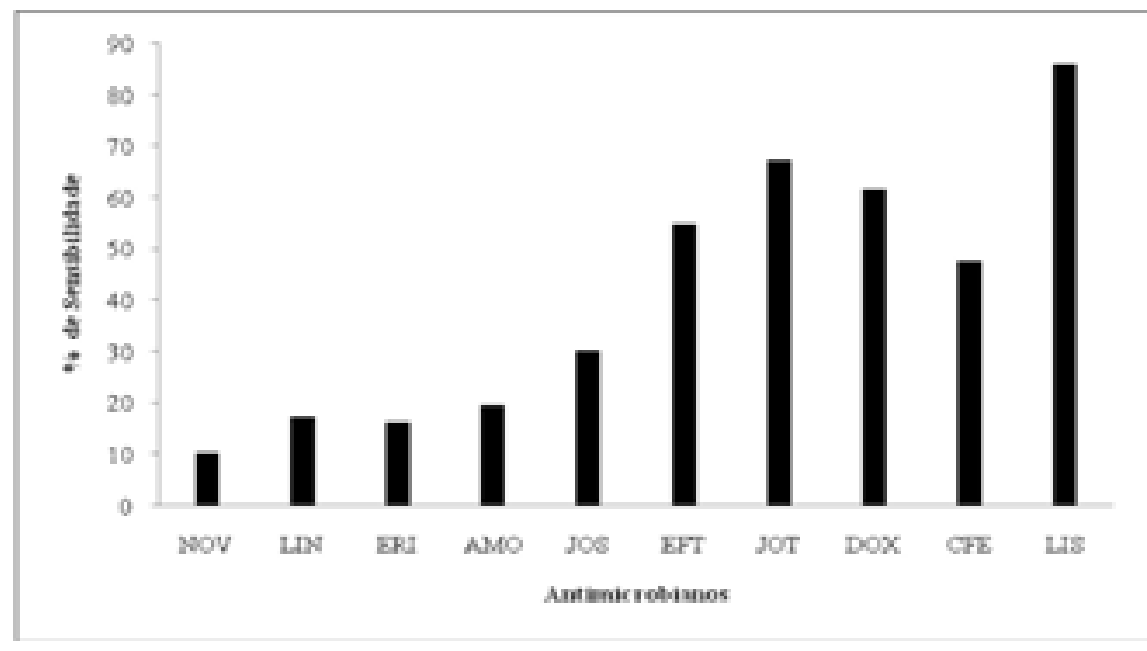

FIGURA 1. Percentual de sensibilidade aos antimicrobianos de isolados de mastite ovina. NOV (novobiocina); LIN (lincomicina); ERI (eritromicina); AMO (amoxicilina); JOS (josamicina); EFT (ceftiofur); JOT (josamicina + trimetoprim); DOX (doxiciclina); CFE (cefalexina); LIS (lincomicina + estreptomicina). 


\section{CONCLUSÕES}

Neste estudo, observou-se que os Staphylococcus spp são os agentes comumente envolvidos nos casos de mastite subclínica em ovelhas. A associação entre lincomicina + estreptomicina e josamicina + trimetoprim foi a mais eficiente nos testes de sensibilidade in vitro contra os agentes da mastite ovina.

\section{REFERÊNCIAS}

BERGONIER, D.; BERTHELOT, X. New advances in epizootiology and control of ewe mastitis. Livestock Production Science, v. 79, p. 1-16, 2003.

BERRIATUA, E.; ZILUAGA, I.; MIGUEL-VIRTO, C.; URIBARREN, P.; JUSTE, R.; LAEVENS, S.; VANDAMME, P.; GOVAN, J. R. Outbreak of subclinical mastitis in a flock of dairy sheep associated with Burkholderia cepacia complex infection. Journal of Clinical Microbiology, v. 39, p. 990-994, 2001.

BLOOD, D. C.; RADOSTITS, O. M.; HENDERSON, J. A. Veterinary medicine. 7- ed. London : Bailiére Tindall, 1994. 1763 p.

BRABES, K. C. S.; ANDRADE, N. J.; MENDONÇA, R. C. S.; LIMA, J. C.; LOPES, F. A. Identificação e classificação de enterotoxinas produzidas por Staphylococcus spp. isolados de ar de ambiente, manipuladores e de superfícies em uma indústria de laticínios. Revista do Instituto de Laticínios Cândido Tostes, v. 58, n. 333, p. 33-38, 2003.

CLEMENTS, A. C.; TAYLOR, D. J.; FITZPATRICK, J. L. Evaluation of diagnostic procedures for subclinical mastitis in meat-producing sheep. Journal of Dairy Research, v. 70, p. 139-148, 2003.

CONTRERAS, A.; LUENGO, C.; SANCHEZ, A.; CORRALES, J. C. The role of intramammary pathogens in dairy goats. Livestock Production Science, v. 79, p. 273-283, 2003.

CONTRERAS, A.; SIERRA, D.; SÁNCHEZ, A.; J. C.; CORRALES, J. C.; MARCO, J. C.; PAAPE, M. J.; GONZALO, C. Mastitis in small ruminants. Small Ruminant Research, v. 68, p. 145-163, 2007.

COUTINHO, D. A.; COSTA, J. N.; RIBEIRO, M. G.; TORRES, $\mathrm{J}$. A. Etiologia e sensibilidade antimicrobiana in vitro de bactérias isoladas de ovelhas da raça Santa Inês com mastite subclínica. Revista Brasileira de Saúde e Produção Animal, v. 7, n. 2, p. 139-151, 2006.

DEINHOFER, M.; PERNTHANER, A. Staphylococcus spp. as mastitis related pathogens in goat milk. Veterinary Microbiology, v. 43, p. 161-166, 1995.
FREITAS, M. F. L.; PINHEIRO JÚNIOR, J. W.; STAMFORD, T. L. M.; RABELO, S. S. A.; SILVA, D. R.; SILVEIRA FILHO, V. M.; SANTOS, F. G. B.; SENA, M. J.; MOTA, R. A. Perfil de sensibilidade antimicrobiana in vitro de Staphylococcus coagulase positivos isolados de leite de vacas com mastite no agreste do estado de Pernambuco, Arquivos do Instituto Biológico, v. 72, n. 2, p. 171-177, 2005.

GONZÁLEZ-RODRÍGUEZ, M. C.; CÁRMENES, P. Evaluation of the California mastitis test as a discriminant method to detect subclinical mastitis in ewes. Small Ruminant Research, v. 21, p. 245-250, 1996.

GONZALO, C.; TARDAGUILA, J. A.; DE LA FUENTE, L. F.; SAN PRIMITIVO, F. Effects of selective and complete dry therapy on prevalence of intramammary infection and on milk yield in the subsequent lactation in dairy ewes. Journal of Dairy Research, v. 71, p. $33-38,2004$.

HUESTON, W. D.; HARTWIG, N. R.; JUDY, J. K. Detection of ovine intramammary infection with the California mastitis test. Journal of the American Veterinary Medical Association, v. 188, p. 522-524, 1986.

LANGONI, H.; ARAÚJO, W. N.; SILVA, A. V.; SOUZA, L. C. Tratamento da mastite bovina com amoxicilina e enrofloxacina bem como com a sua associação. Arquivos do Instituto Biológico, v. 67 , n. 2, p. 177-180, 2000.

LEITNER, G.; CHAFFER, M.; SHAMAY, A.; SHAPIRO, F.; MERIN, U.; EZRA, E.; SARAN, A.; SILANIKOVE, N. Changes in milk composition as affected by subclinical mastitis in sheep. Journal of Dairy Science, v. 87, p. 46-52, 2004.

LOLLAI, S. A.; ZICCHEDDU, M.; MAUROB, C. D.; MANUNTA, D.; NUDDAB, A.; LEORI, G. Profile and evolution of antimicrobial resistence of ovine mastitis pathogens. Small Ruminant Research, v. 74, p. 249-254, 2008.

MARGUET, E. R.; VILANOVA, C. P.; SALGADO, E. Study of subclinical mastitis in a sheep dairy herd. Veterinaria-Argentina, v. 163, n. 17, p. 190-197, 2000.

NCCLS. Development of in vitro susceptibility testing criteria and quality control parameters for veterinary antimicrobial agents. Approved guideline M37-A. Wayne, Pa: NCCLS, 1999.

PRESTES, D. S.; FILATI, A.; CECIM, M. S. Suscetibilidade à mastite: fatores que a influenciam - uma revisão. Revista Faculdade Zootecnia Veterinária e Agronomia, v. 9, n. 1, p. 48-59, 2003.

QUINN, P. J.; CARTER, M. E.; MARKEY, B.; CARTER, G. R. Clinical veterinary Medicine. London: Mosby-Year, 1994. $648 \mathrm{p}$. 
SANTOS, C. D. M. Staphylococcus sp e enterobactérias isoladas de mastite recorrente em oito rebanhos da região de Uberlândia, MG: perfil de suscetibilidade aos antimicrobianos. 2006. $54 \mathrm{f}$. Dissertação (Mestrado em Ciências Veterinárias) - Universidade Federal de Uberlândia, Uberlândia, 2006. Disponível em http:// www.mestrado.famev.ufu.br/.

SILANIKOVE, N.; SHAPIRO, F.; LEITNER, G.; MERIN, U. Subclinical mastitis affects the plasmin system, milk composition and curd yield in sheep and goats: comparative aspects. In: HOGEVEEN, H. (Ed.). Mastitis in dairy production. The Netherlands: Wageningen Academic Press Publishers, 2005. p. 511-516.
TAVARES, W. Bactérias gram positivas: resistência do estafilococo, do enterococo e do pneumococo aos antimicrobianos. Revista da Sociedade Brasileira de Medicina Tropical, v. 33, n. 3, p. 281-301, 2000.

UDO, E. E.; AL-BUSTAN, M. A.; JACOB, L. E.; CHUGH, T. D. Enterotoxin production by coagulase-negative staphylococci in restaurant workers from Kuwait City may be a potential cause of food poisoning. Journal of Medical Microbiology, v. 48, p. 819-823, 1999.

Protocolado em: 10 dez. 2008. Aceito em: 31 ago. 2009. 